\title{
Erlotinib in the treatment of advanced squamous cell NSCLC
}

\author{
O. FIALA ${ }^{1, *}$, M. PESEK ${ }^{2}$, J. FINEK ${ }^{1}$, J. KREJCI ${ }^{3}$, L. HAVEL ${ }^{3}$, M. HRNCIARIK ${ }^{4}$, F. SALAJKA ${ }^{4}$, Z. BORTLICEK ${ }^{5}$, L. BENESOVA ${ }^{6}$, M. MINARIK ${ }^{6}$
}

${ }^{1}$ Department of Oncology and Radiotherapy, Medical School and Teaching Hospital Pilsen, Charles University Prague, Czech Republic; ${ }^{2}$ Department of Tuberculosis and Respiratory Diseases, Medical School and Teaching Hospital Pilsen, Charles University Prague, Czech Republic; ${ }^{3}$ Department of Pneumology and Thoracic Surgery, University Hospital Prague-Bulovka, Charles University Prague, Czech Republic; ${ }^{4}$ Pulmonary Department, Faculty of Medicine and University Hospital Hradec Kralove, Charles University Prague, Czech Republic; ${ }^{5}$ Institute of Biostatistics and Analyses, Masaryk University, Brno, Czech Republic; ${ }^{6}$ Center for Applied Genomics of Solid Tumors (CEGES), Genomac Research Institute, Prague

*Correspondence: fiala.o@centrum.cz

Received February 12, 2013 / Accepted April 2, 2013

\begin{abstract}
Erlotinib is an epidermal growth factor receptor tyrosine-kinase inhibitor. Clinical trials have shown its efficacy in advanced non-small cell lung cancer (NSCLC). We conducted a large retrospective study based on clinical experience aiming to prove erlotinib's efficacy and safety in patients with advanced-stage squamous cell NSCLC. Totally 375 patients with advanced-stage (IIIB, IV) squamous cell NSCLC were treated with erlotinib. Erlotinib was continued until disease progression or intolerable toxicity. 1 (0.3\%) complete response (CR), 28 (7.5\%) partial responses (PR) and 198 (52.8\%) stable diseases (SD) were achieved. Overall response rate (ORR) and disease control rate (DCR) were 7.8\% and 60.5\%, respectively. Median progression-free survival (PFS) was 3.0 months and median overall survival (OS) was 7.6 months. PFS of patients with CR/PR, SD and PD were 7.6, 3.9 and 1.0 months, respectively $(\mathrm{P}<0.001)$. OS of patients with $\mathrm{CR} / \mathrm{PR}, \mathrm{SD}$ and PD were $13.3,10.9$ and 3.8 months, respectively $(\mathrm{P}<0.001)$. The most common adverse effects were rash and diarrhoea. In conclusion erlotinib is effective and well-tolerated in patients with advanced-stage squamous cell NSCLC.
\end{abstract}

Key words: squamous cell, NSCLC, erlotinib, targeted treatment, EGFR-TKI

Lung cancer is one of the most common human malignant diseases and the leading cause of cancer-related deaths worldwide [1]. Non-small cell lung cancer (NSCLC) is the most common histological type of lung cancer [2]. NSCLC is divided into four major histological subtypes including adenocarcinoma (ADC), squamous cell carcinoma (SCC), large-cell carcinoma (LCC) and not otherwise specified (NOS) [3]. The most frequent histological subtype is ADC, but SCC accounts for approximately 25-30\% of all lung cancer cases [4]. Considerable progress in the field of NSCLC has been reached and several new effective agents have been approved for the treatment of patients with advanced-stage NSCLC including pemetrexed, bevacizumab, gefitinib, crizotinib and erlotinib. The treatment efficacy of pemetrexed and bevacizumab is limited to patients with non-squamous histology $[5,6,7]$. The treatment efficacy of gefitinib and crizotinib is limited to patients harbouring specific genetic alterations occurring predominantly in patients with ADC such as activating epidermal growth factor receptor (EGFR) mutations in the case of gefitinib $[8,9]$ and anaplastic lymphoma kinase (ALK) translocations in the case of crizotinib [10, 11]. Erlotinib is the only one of the novel targeted agents used for the treatment of patients with advanced-stage SCC in current clinical practice [12]. Erlotinib is an orally administered low-molecular tyrosine kinase inhibitor targeting epidermal growth factor receptors. Results of the randomised phase III BR.21 and SATURN clinical trials showed that erlotinib treatment was effective even in patients with SCC, and a significant survival benefit was achieved in this group [13, 14]. Despite several studies evaluating erlotinib efficacy in terms of clinical practice have been published recently, analysis performed on a large cohort of patients is still lacking. Thus we conducted this large retrospective study based on clinical experience aiming to prove erlotinib's efficacy in the treatment of patients with advanced-stage SCC.

\section{Patients and methods}

Study design and treatment. We analysed data of patients with cytologically or histologically confirmed locally-advanced 
(IIIB) or metastatic (IV) stage squamous cell NSCLC. Patients were diagnosed and treated at the following three departments: Department of Tuberculosis and Respiratory Diseases, Medical School and Teaching Hospital Pilsen; Department of Pneumology and Thoracic Surgery, University Hospital Prague-Bulovka and Pulmonary Department, Faculty of Medicine and University Hospital Hradec Kralove. Patients were treated with oral erlotinib, which was approved at a standard daily dose of 150 $\mathrm{mg}$; dose interruption or reduction (in $50 \mathrm{mg} /$ day decrements) was permitted in the event of treatment-related toxicity. The treatment was continued until disease progression or development of intolerable toxic effects.

Clinical assessments and statistical analysis. The treatment was prospectively monitored and the clinical course of patients was continuously assessed at specific time points. Clinical follow-up exams included physical examination, plain chest skiagram and routine laboratory tests. These were performed every 3-4 weeks. CT or PET-CT exams were performed after 2 or 3 months of treatment with erlotinib. The best treatment response was assessed by investigators in terms of complete response (CR), partial response (PR), stable disease (SD) and progressive disease (PD) using Response Evaluation Criteria in Solid Tumors (RECIST) [15]. The overall response rate (ORR) was defined as the sum of CR and PR. The disease control rate (DCR) was defined as the sum of CR, PR and SD. Standard frequency tables and summary statistics, i.e. median and percentiles, were used to describe sample data set. Progression-free survival (PFS) was determined from the date of erlotinib initiation until the date of first documented progression or death. Overall survival (OS) was determined from the date of erlotinib initiation until the date of death. Adverse events and serious adverse events were recorded and classified by grade according to the National Cancer Institute Common Terminology Criteria for Adverse Events version 3.0. [16]. The visualizations of PFS and OS as well as the estimations of survival probabilities were performed using Kaplan-Meier survival curves; all point estimates were accompanied with $95 \%$ confidence intervals. The differences in survival were tested using the log-rank test. As a level of statistical significance, $P=0.05$ was used.

EGFR mutation analysis. Tumor specimens acquired during an initial bronschoscopic examination were evaluated by a senior cytologist using a regular giemsa staining. In a few cases a tumor biopsy was processed into formalin-fixed paraffin embedded (FFPE) histology sections. The cytology slides or FFPE sections, were submitted for molecular genetic testing, including detection of somatic mutations in the EGFR gene. If necessary, tumor cells were carefully selected and removed from the samples by laser micro-dissection using a P.A.L.M. micro-laser instrument [Carl Zeiss MicroImaging $\mathrm{GmbH}$, Germany]. The micro-dissected cells were collected directly into the PCR buffer and processed without a special DNA extraction step. In all other cases the DNA was extracted from tissue cells by a standard spin column procedure using JetQuick Tissue DNA Isolation Kit [GENOMED GmbH,
Loehne, Germany]. The mutations in exons 19 and 21 of the EGFR gene were analysed by Genoscan EGFR kits [Genomac International, Prague, Czech Republic] utilizing a denaturing capillary electrophoresis (DCE) technique on an ABI PRISM 3100 16-capillary genetic analyzer. Detected mutations were identified by regular DNA sequencing using a BigDye v 3.0 chemistry (Applied Biosystems, Foster City, CA). In rare cases, where the overall fraction of mutated DNA was below the $20 \%$ minimum required for DNA sequencing, mutation was identified indirectly after forming only a homoduplex fragment with a given known mutation reference standard.

\section{Results}

Patient characteristics. A total of 1,354 patients with advanced stage NSCLC were treated with erlotinib between 2005 and 2012. 375 patients with advanced squamous cell NSCLC and at least 6-months follow-up were enrolled in this retrospective study. The baseline characteristics are summarized in the Table 1 . The median age was 64 years (5\%-95\% range 52-78 years). 304 (81.1\%) patients were male, 362 (96.5\%) patients had a positive smoking history, $275(73.3 \%)$ patients had stage IV disease and 209 (55.7\%) patients had ECOG PS 0 or 1 . The majority of patients $(339,90.4 \%)$ had received at least one previous chemotherapy regimen. The median duration of erlotinib treatment was 2.4 months (5\%-95\% range $0.5-10.8$ ). The treatment was ended in $360(96.0 \%)$ patients at the time of data evaluation in January 2013.

Table 1. Baseline patient characteristics

\begin{tabular}{lc}
\hline Characteristics & $\mathbf{n}=\mathbf{3 7 5}$ \\
\hline Gender, $\mathrm{n}(\%)$ & $304(81.1)$. \\
$\quad$ Male & $71(18.9)$ \\
$\quad$ Female & \\
Age (years) & $64(52-78)$ \\
$\quad$ Median (range) & \\
Smoking, $\mathrm{n}(\%)$ & $13(3.5)$ \\
$\quad$ Never-smoker & $163(43.5)$ \\
Former-smoker & $199(53.1)$ \\
Current-smoker & \\
Stage, $\mathrm{n}(\%)$ & $100(26.7)$ \\
IIIB & $275(73.3)$ \\
IV & \\
Treatment line, $\mathrm{n}(\%)$ & $36(9.6)$ \\
First & $163(43.5)$ \\
Second & $170(45.3)$ \\
Third & $6(1.6)$ \\
Fourth or more & \\
ECOG PS, $\mathrm{n}(\%)$ & $16(4.3)$ \\
0 & $193(51.5)$ \\
1 & $160(42.7)$ \\
2 & $6(1.6)$ \\
3 and 4 &
\end{tabular}



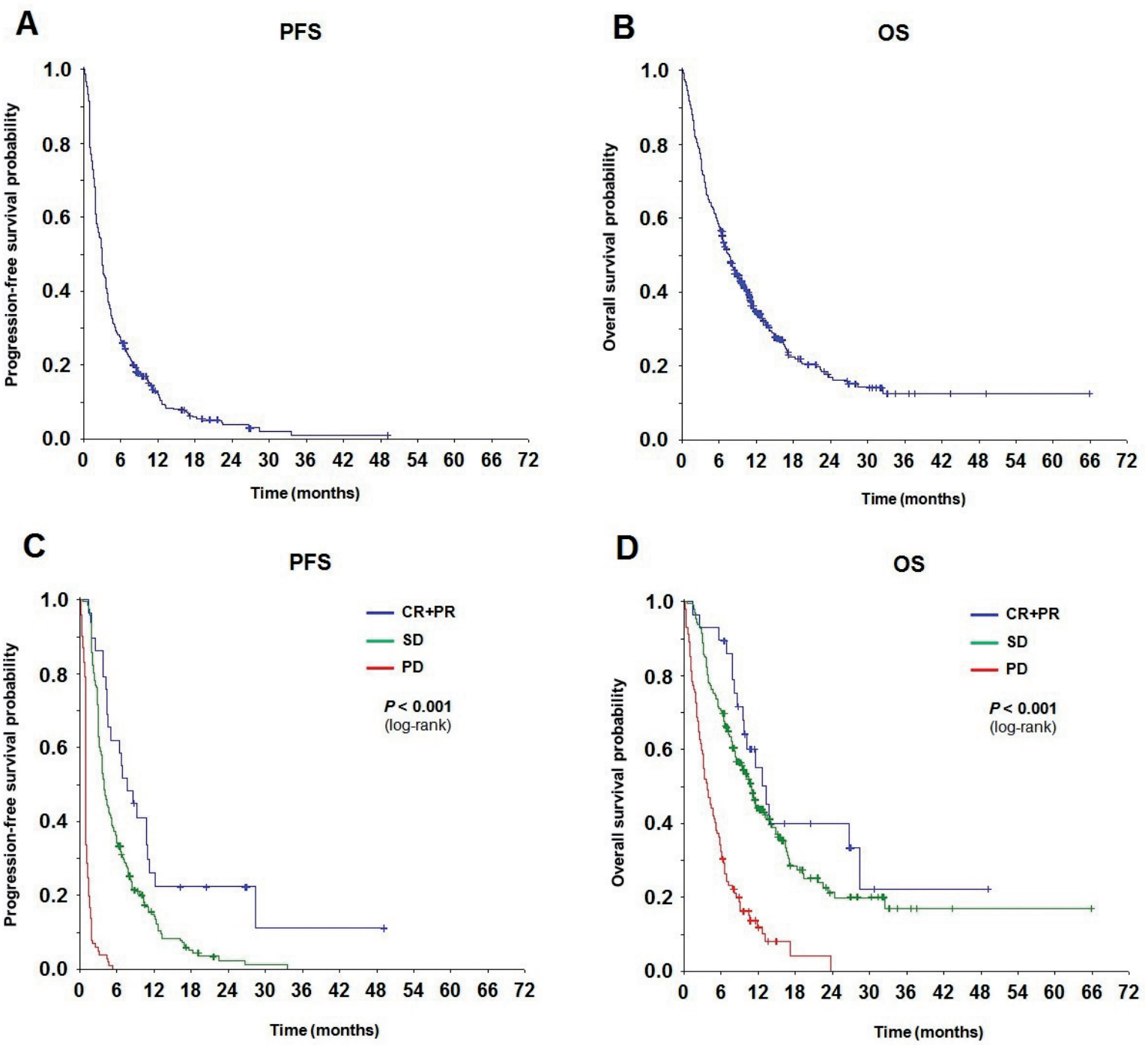

Figure 1. Kaplan-Meier plots showing PFS (A) and OS (B) of all SCC patients treated with erlotinib and comparison of PFS (C) and OS (D) according to best response.

Response and survival. CR was achieved in $1(0.3 \%)$ patient, PR was achieved in 28 (7.5\%) patients, SD was achieved in 198 (52.8\%) patients, PD occurred in $102(27.2 \%)$ patients and the

Table 2. Best response to erlotinib treatment

\begin{tabular}{lcc}
\hline Best response & $\mathbf{n}$ & $\%$ \\
\hline Complete response (CR) & 1 & 0.3 \\
Partial response (PR) & 28 & 7.5 \\
Overall response rate (ORR) & 29 & 7.8 \\
Stable disease (SD) & 198 & 52.8 \\
Disease control rate (DCR) & 227 & 60.5 \\
Progressive disease & 102 & 27.2 \\
Not evaluated & 46 & 12.3 \\
\hline
\end{tabular}

best treatment response was not evaluated in $46(12.3 \%)$ patients. The ORR and DCR were $7.8 \%$ and $60.5 \%$, respectively. The results of the best treatment response are summarized in Table 2. The median of PFS was 3.0 months (95\% CI 2.6-3.3) [Fig. 1A] and the median of OS was 7.6 months (95\% CI 6.5-8.7) [Fig. 1B]. The median PFS of patients with CR/PR, SD and PD was 7.6 (95\% CI 4.2-11.1), 3.9 (95\% CI 3.4-4.4) and 1.0 months (95\% CI 0.9-1.1), respectively; the difference was statistically significant $(P<0.001)$ [Fig. 1C ]. The median OS of patients with CR/PR, SD and PD was 13.3 (95\% CI 10.3-16.3), 10.9 (95\% CI 9.5-12.2) and 3.8 months (95\% CI 2.8-4.7), respectively; the difference was statistically significant $(P<0.001)$ [Fig. 1D].

Safety and tolerability. Treatment was accompanied by an adverse event (AE) in 186/375 (49.6\%) patients. The most commonly recorded AE was skin rash, occurring in 156/375 

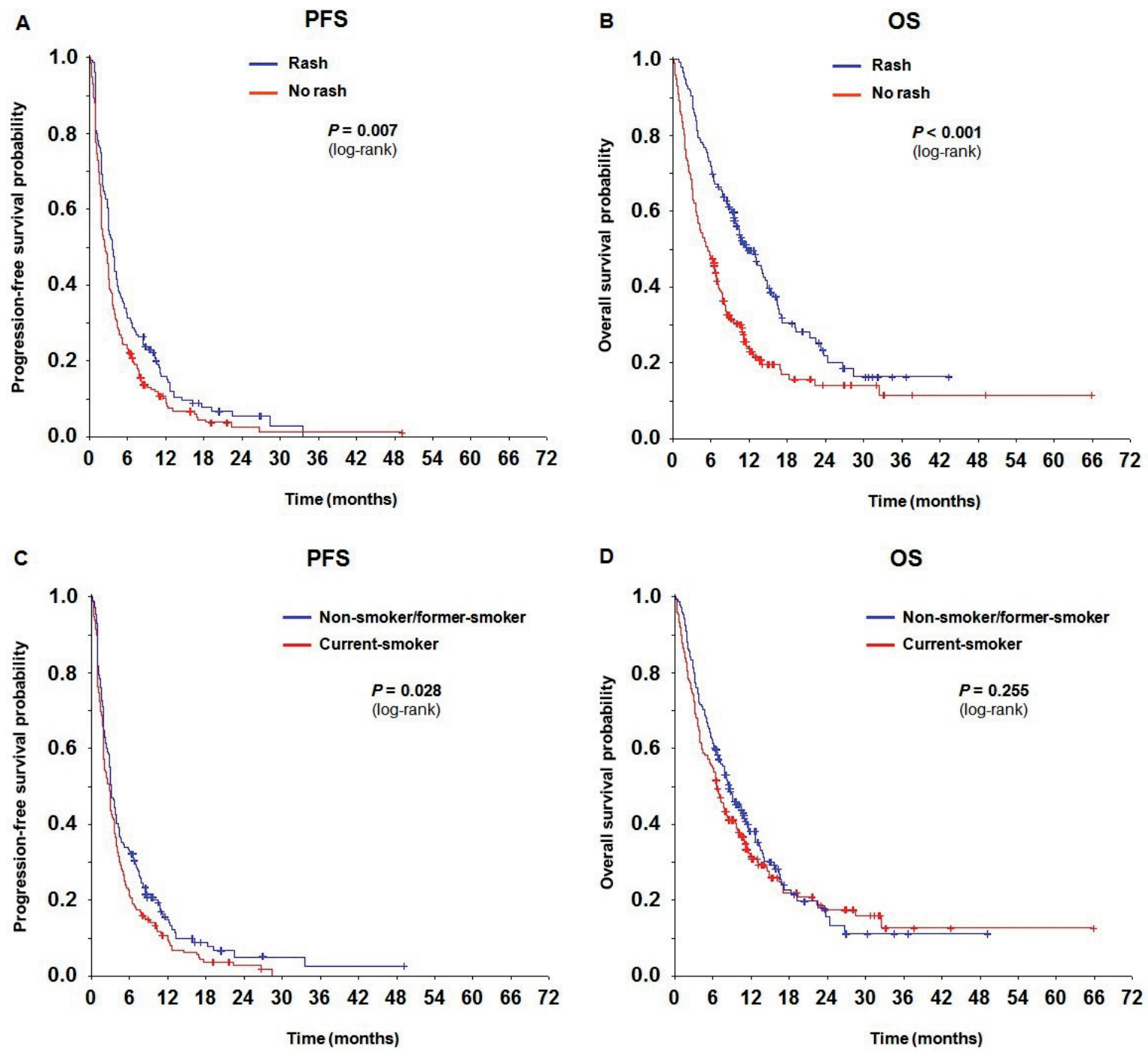

E

PFS

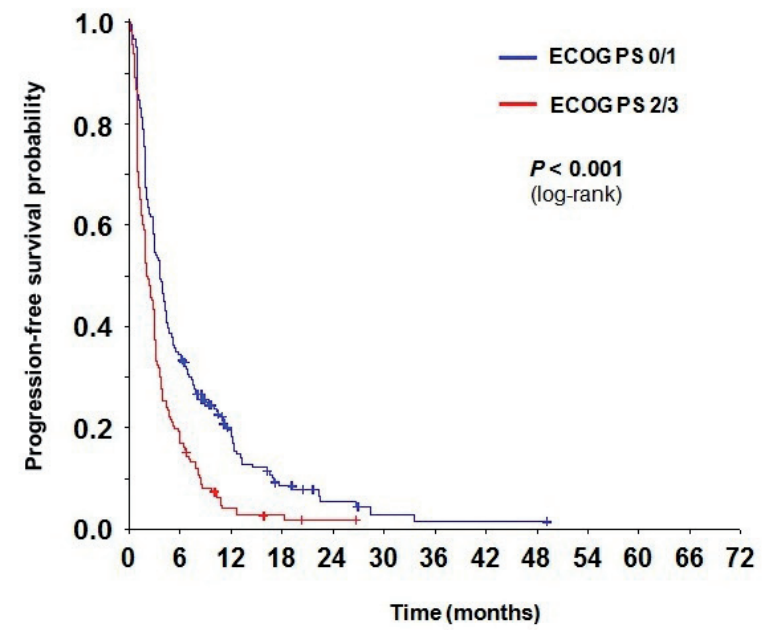

$\mathbf{F}$

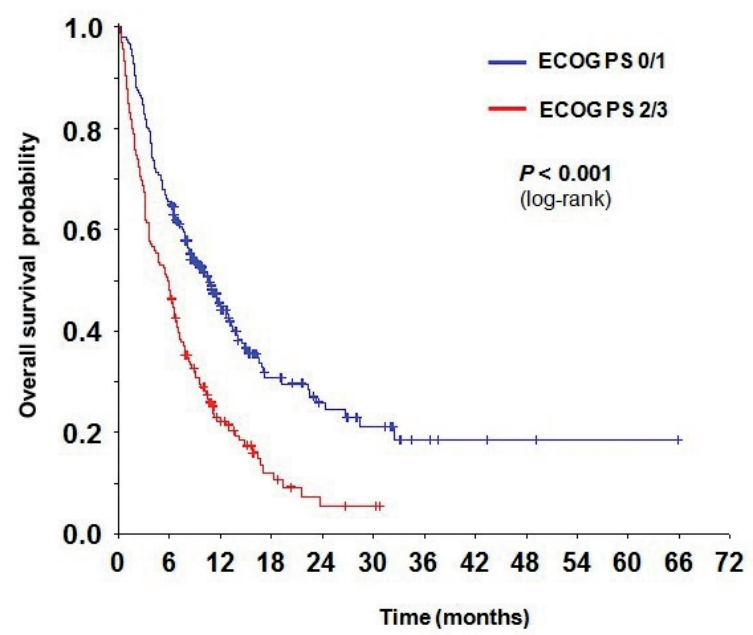

Figure 2. Kaplan-Meier plots showing comparison of PFS and OS in selected subgroups according to: occurrence of skin rash (A, B), smoking history (C, D) and ECOG PS (E, F). 
(41.6\%) patients followed by diarrhoea occurring in 64/375 (17.1\%) patients. Other often-recorded AEs included soft tissue infection $(11 / 375 ; 2.9 \%)$, anorexia $(8 / 375 ; 2.1 \%)$ and nausea $(6 / 375 ; 1.6 \%)$. Skin rash grade $3 / 4$ was recorded in $33 / 375(8.8 \%)$ patients and diarrhoea grade $3 / 4$ was recorded in $15 / 375(4.0 \%)$ patients. The AEs led to termination of treatment in 12/360 (3.3\%) patients. No ILD-like events or cases of toxic death were reported.

Survival in selected subgroups. The median PFS of patients with skin rash was 3.6 vs. 2.4 months of patients without skin rash; the difference was statistically significant $(P=0.007)$ [Fig.2A]. The median OS of patients with skin rash was 11.6 vs. 5.5 months of patients without skin rash; the difference was statistically significant $(P<0.001)$ [Fig.2B]. The median PFS of never/former-smokers was 3.1 vs. 2.8 months in current-smokers; the difference was statistically significant $(P=0.028)$ [Fig.2C]. The median OS of never/ former-smokers was 8.4 vs. 6.6 months in current-smokers; the difference was not statistically significant $(P=0.255)$ [Fig.2D]. The median PFS of patients with ECOG PS 0/1 was 3.7 vs. 2.1 months of patients with ECOG PS 2/3; the difference was statistically highly significant $(P<0.001)$ [Fig.2E]. The median OS of patients with ECOG PS $0 / 1$ was 10.7 vs. 5.8 months of patients with ECOG PS $2 / 3$; the difference was statistically highly significant $(P<0.001)[$ Fig.2F]. The median PFS of patients treated in the first, second, third or higher treatment line were 3.6 months (95\% CI 2.1-5.1), 2.8 months (95\% CI 2.2-3.3) and 3.0 months (95\% CI 2.3-3.6) respectively. The median OS of patients treated in the first, second, third or higher treatment line were 9.1 months (95\% CI 7.2-11.0), 7.0 months (95\% CI 5.4-8.5) and 7.8 months (95\% CI 6.5-9.1) respectively. There was no statistically significant difference in PFS $(P=0.489)$ nor in OS $(P=0.372)$ between these groups.

EGFR mutation analysis. 87/375 (23.2\%) patients had adequate specimens for EGFR mutation analysis and were successfully tested. Activating EGFR mutations were found in $4(4.6 \%)$ patients including 2 exon 19 deletions and 2 exon 21 point mutations, termed L858R. Among patients harboring the activating EGFR mutation, there were 2 males and 2 females, all with a positive smoking history, $1 \mathrm{PR}$ and 3 SD were achieved, PFS was 3.8, 3.6, 3.0 and 5.0 months respectively and OS was 27.0, 25.5, 11.25 and 6.33 months respectively. Because of the low number of patients harboring the activating EGFR mutation, statistical analysis could not be performed.

\section{Discussion}

In this study, ORR and DCR were achieved in 7.8 and $60.5 \%$ patients, respectively; the median PFS and OS were 3.0 and 7.6 months, respectively. In comparison with the data recently reported by Tseng et al. and Chiang et al. focusing on treatment efficacy of erlotinib in patients with advancedstage SCC, our study showed lower ORR (7.8\% vs. $17.4 \%$ and $16.2 \%)$, but higher DCR (60.5\% vs. $27.2 \%$ and $51.4 \%)$ and longer PFS (3.0 vs. 1.7 and 2.0 months) $[17,18]$. On the other hand, our results are similar to those previously reported by Reck et al., who reported data of a phase IV trial of erlotinib in advanced NSCLC showing ORR between 4 and $17 \%$ and PFS between 2.3 and 3.0 months in a subgroup of patients with SCC [19]. Outstanding survival times were reached especially in patients achieving CR or PR, where the median PFS was 7.6 months and median OS was 13.3 months. The treatment was safe and well-tolerated. The most common AEs were skin rash (41.6\%) and diarrhoea (17.1\%); no ILD-like events or cases of toxic death were reported. We showed longer survival of patients occurring with skin rash compared to those without (PFS: 3.6 vs. 2.4 months, $P=0.007$; OS: 11.6 vs. 5.5 months of patients, $P<0.001$ ). Thus we confirmed the role of skin rash as a marker of erlotinib efficacy, a fact that has been previously reported [20-22]. An important finding in our study was longer PFS of never-smokers or former-smokers in comparison with current-smokers ( 3.1 vs. 2.8 months, $P=0.028$ ). Hamilton et al. reported previously that smoking could significantly influence the pharmacokinetics of erlotinib [23]. Patients receiving erlotinib should be strongly advised to stop smoking. We showed longer survival of patients with PS 0 or 1 in comparison with those with PS 2 or 3 (PFS: 3.7 vs. 2.1 months, $P<0.001$; OS: 10.7 vs. 5.8 months, $P<0.001)$. These results suggest that $P S$ is a strong prognostic factor and that the efficacy of erlotinib treatment in patients with higher PS is limited. On the other hand, the fact should be mentioned that patients with higher PS are not suitable for chemotherapy, thus erlotinib remains the only treatment option for them. Activating EGFR mutations were found in $4 / 87$ (4.9\%) patients, a similar EGFR mutation frequency in SCC has been previously reported by Miyamae et al. [24]. Among patients harboring activating EGFR mutation, $1 \mathrm{PR}$ and 3 $\mathrm{SD}$ were achieved, but relatively short PFS ranging between 3.0 and 5.0 months was reached. Activating EGFR mutations have been well-known as a strong predictive marker of efficacy of treatment with EGFR-TKIs in patients with advanced NSCLC and they are commonly found in ADC, contrasting with their scarce occurrence in SCC [25-33]. Shukuya et al. have published an interesting study demonstrating that the treatment efficacy of gefitinib was significantly inferior in non-adenocarcinoma NSCLC patients harboring activating EGFR mutations compared to those with ADC [34]. Thus the predictive role of activating EGFR mutations in SCC still remains unclear and further research is needed to answer this interesting question.

In conclusion, erlotinib is effective and well-tolerated option for the treatment of patients with locally-advanced or metastatic stage squamous cell NSCLC.

Acknowledgments: The authors would like to thank all patients voluntarily taking part in this study. This work was partially supported by the grant no. 9087 of the Czech Ministry of Health. 


\section{References}

[1] PARKIN DM. Global cancer statistics in the year 2000. Lancet Oncol. 2001; 2: 533-43. http: //dx.doi.org/10.1016/S14702045(01)00486-7

[2] BRAMBILlA E, TRAVIS WD, COLBY TV, CORRIN B, SHIMOSATO Y. The new World Health Organization classification of lung tumors., Eur Respir J. 2001; 18: 1059-68. http: //dx.doi.org/10.1183/09031936.01.00275301

[3] TRAVIS WD, BRAMBILLAE E, MULLER-HERMELINK HK, HARRIS CC. World Health Organization Classification of tumors. Pathology and genetics tumors of the lung, pleura, thymus and heart. Lyon : IARC Press, 2004.

[4] WAHBAH M, BOROUMAND N, CASTRO C, EL-ZEKY F, ELTORKY M. Changing trends in the distribution of the histologic types of lung cancer: a review of 4,439 cases. Ann Diagn Pathol. 2007; 2: 89-96. http: //dx.doi.org/10.1016/ j.anndiagpath.2006.04.006

[5] SCAGLIOTTI GV, PARIKH P, VON PAWEL J, BIESMA B, VANSTEENKISTE J et al. Phase III study comparing cisplatin plus gemcitabine with cisplatin plus pemetrexed in chemotherapy-naive patients with advanced-stage non-small-cell lung cancer. J Clin Oncol. 2008; 26: 3543-3551. http: //dx.doi. org/10.1200/JCO.2007.15.0375

[6] PAZ-ARES L, DE MARINIS F, DEDIU M, THOMAS M, PUJOL JL et al. Maintenance therapy with pemetrexed plus best supportive care versus placebo plus best supportive care after induction therapy with pemetrexed plus cisplatin for advanced non-squamous non-small-cell lung cancer (PARAMOUNT): a double-blind, phase 3, randomised controlled trial. Lancet Oncol. 2012; 3: 247-55. http: //dx.doi.org/10.1016/S14702045(12)70063-3

[7] JOHNSON DH, FEHRENBACHER L, NOVOTNY WF, HERBST RS, NEMUNAITIS JJ et al. Randomized phase II trial comparing bevacizumab plus carboplatin and paclitaxel with carboplatin and paclitaxel alone in previously untreated locally advanced or metastatic non-small-cell lung cancer. J Clin Oncol. 2004; 22: 2184-91. http: //dx.doi.org/10.1200/ LCO.2004.11.022

[8] THATCHER N, CHANG A, PARIKH P, RODRIGUES PEREIRA J, CIULEANU T et al.. Gefitinib plus best supportive care in previously treated patients with refractory advanced non-small-cell lung cancer: results from a randomised, placebo-controlled, multicentre study (Iressa Survival Evaluation in Lung Cancer). Lancet. 2005; 9496: 1527-37. http: //dx.doi. org/10.1016/S0140-6736(05)67625-8

[9] MOK TS, WU YL, THONGPRASERT S, YANG CH, CHU DT et al. Gefitinib or carboplatin-paclitaxel in pulmonary adenocarcinoma. N Engl J Med. 2009; 10: 947-57. http: //dx.doi. org/10.1056/NEJMoa0810699

[10] BANG YJ. The potential for crizotinib in non-small cell lung cancer: a perspective review. Ther Adv Med Oncol. 2011; 6: 279-91. http: //dx.doi.org/10.1177/1758834011419002

[11] KIM D-W, AHN M-J, SHI Y, DE PAS TM, YANG P-CH et al. Results of a global phase II study with crizotinib in advanced ALK-positive non-small cell lung cancer (NSCLC). J Clin Oncol. 2012 (suppl; abstr 7533).
[12] National Comprehensive Cancer Network: NCCN Clinical Practice Guidelines in Oncology for Non-Small Cell Lung Cancer V.3.2011.

[13] CLARK GM, ZBOROWSKI DM, SANTABARBARA P, DING $\mathrm{K}$, WHITEHEAD $\mathrm{M}$ et al.Smoking history and epidermal growth factor receptor expression as predictors of survival benefit from erlotinib for patients with non-small-cell lung cancer in the National Cancer Institute of Canada Clinical Trials Group study BR.21. Clin Lung Cancer. 2006; 6: 389-94. http: //dx.doi.org/10.3816/CLC.2006.n.022

[14] CAPPUZZO F, CIULEANU T, STELMAKH L, CICENAS S, SZCZESNA A et al. Erlotinib as maintenance treatment in advanced non-small-cell lung cancer: a multicentre, randomised, placebo-controlled phase 3 study. Lancet Oncol. 2010; 11: 521-29. http: //dx.doi.org/10.1016/S1470-2045(10)70112-1

[15] THERASSE P, ARBUCK SG, EISENHAUER EA, WANDERS J, KAPLAN RS et al. New guidelines to evaluate the response to treatment in solid tumors. European Organization for Research and Treatment of Cancer, National Cancer Institute of the United States, National Cancer Institute of Canada. J Natl Cancer Inst. 2000; 3: 205-16. http: //dx.doi.org/10.1093/ jnci/92.3.205

[16] Cancer Therapy Evaluation Program, Common Terminology Criteria for Adverse Events, Version 3.0.http: //ctep.cancer. gov/protocolDevelopment/electronic_applications/docs/ ctcaev3.pdf

[17] TSENG JS, YANG TY, CHEN KC, HSU KH, CHEN HY et al. Retrospective study of erlotinib in patients with advanced squamous lung cancer. Lung Cancer. 2012; 1: 128-33. http: //dx.doi.org/10.1016/j.lungcan.2012.02.012

[18] CHIANG CL, TSAI CM, CHOU TY, CHEN YM, LAI SL et al. Erlotinib in patients with advanced lung squamous cell carcinoma. Cancer Chemother Pharmacol. 2013; 71: 203-8. http: //dx.doi.org/10.1007/s00280-012-1997-5

[19] RECK M, VAN ZANDWIJK N, GRIDELLI C, BALIKO Z, RISCHIN D et al. Erlotinib in advanced non-small cell lung cancer: efficacy and safety findings of the global phase IV Tarceva Lung Cancer Survival Treatment study. J Thorac Oncol. 2010; 10: 1616-22. http: //dx.doi.org/10.1097/ ITO.0b013e3181f1c7b0

[20] WACKER B, NAGRANI T, WEINBERG J, WITT K, CLARK $\mathrm{G}$ et al. Correlation between development of rash and efficacy in patients treated with the epidermal growth factor receptor tyrosine kinase inhibitor erlotinib in two large phase III studies. Clin Cancer Res. 2007; 13: 3913-21. http: //dx.doi. org/10.1158/1078-0432.CCR-06-2610

[21] FAEHLING M, ECKERT R, KUOM S, KAMP T, STOIBER $\mathrm{KM}$ et al. Benefit of erlotinib in patients with non-small-cell lung cancer is related to smoking status, gender, skin rash and radiological response but not to histology and treatment line. Oncology. 2010; 3-4: 249-58. http://dx.doi.org/10.1159/ 000315731

[22] FIALA O, PESEK M, FINEK J, KREJCI J, RICAR J et al. Skin Rash as Useful Marker of Erlotinib Efficacy in NSCLC and Its Impact on Clinical Practice. Neoplasma. 2013; 1: 26-32.

[23] HAMILTON M, WOLF JL, RUSK J, BEARD SE, CLARK GM et al. Effects of smoking on the pharmacokinetics of 
erlotinib. Clin Cancer Res. 2006; 7: 2166-71. http: //dx.doi. org/10.1158/1078-0432.CCR-05-2235

[24] MIYAMAE Y, SHIMIZU K, HIRATO J, ARAKI T, TANAKA $K$ et al. Significance of epidermal growth factor receptor gene mutations in squamous cell lung carcinoma. Oncol Rep. 2011; 4: 921-8.

[25] LYNCH TJ, BELL DW, SORDELLA R, GURUBHAGAVATULA S, OKIMOTO RA et al. Activating mutations in the epidermal growth factor receptor underlying responsiveness of non-small-cell lung cancer to gefitinib., $\mathrm{N}$ Engl J Med. 2004; 21: 2129-39. http: //dx.doi.org/10.1056/ NEJMoa040938

[26] PAEZ JG, JANNE PA, LEE JC, TRACY S, GREULICH H et al. EGFR mutations in lung cancer: correlation with clinical response to gefitinib therapy. Science. 2004; 5676: 1497-500. http: //dx.doi.org/10.1126/science.1099314

[27] GANDHI J, ZHANG J, XIE Y, SOH J, SHIGEMATSU H et al. Alterations in genes of the EGFR signaling pathway and their relationship to EGFR tyrosine kinase inhibitor sensitivity in lung cancer cell lines. PLoS One. 2009; 2: e4576. http: //dx.doi. org/10.1371/journal.pone.0004576

[28] EBERHARD DA, JOHNSON BE, AMLER LC, GODDARD $\mathrm{AD}$, HELDENS SL et al. Mutations in the epidermal growth factor receptor and in KRAS are predictive and prognostic indicators in patients with non-small-cell lung cancer treated with chemotherapy alone and in combination with erlotinib. J Clin Oncol. 2005; 25: 5900-9. http: //dx.doi.org/10.1200/ $\underline{\mathrm{CCO} .2005 .02 .857}$
[29] ZHU CQ, DA CUNHA SANTOS G, DING K, SAKURADA A, CUTZ JC et al. Role of KRAS and EGFR as biomarkers of response to erlotinib in National Cancer Institute of Canada Clinical Trials Group Study BR.21. J Clin Oncol. 2008; 26: 4268-75. http: //dx.doi.org/10.1200/JCO.2007.14.8924

[30] PESEK M, BENESOVA L, BELSANOVA B, MUKENSNABL P, BRUHA F et al. Dominance of EGFR and insignificant KRAS mutations in prediction of tyrosine-kinase therapy for NSCLC patients stratified by tumor subtype and smoking status. Anticancer Res. 2009; 7: 2767-73.

[31] ZHANG Z, STIEGLER AL, BOGGON TJ, KOBAYASHI S, HALMOS B. EGFR-mutated lung cancer: a paradigm of molecular oncology. Oncotarget. 2010; 7: 497-514.

[32] SEQUIST LV, BELL DW, LYNCH TJ, HABER DA. Molecular predictors of response to epidermal growth factor receptor antagonists in non-small-cell lung cancer. J Clin Oncol. 2007; 5: 587-95. http: //dx.doi.org/10.1200/JCO.2006.07.3585

[33] GANDARA DR, LARA PN JR, MACK P, SCAGLIOTTI G. Individualizing therapy for non-small-cell lung cancer: a paradigm shift from empiric to integrated decision-making. Clin Lung Cancer. 2009; 3: 148-50. http: //dx.doi.org/10.3816/ CLC.2009.n.020

[34] SHUKUYA T, TAKAHASHI T, KAIRA R, ONO A, NAKAMURA $Y$ et al. Efficacy of gefitinib for non-adenocarcinoma non-small-cell lung cancer patients harboring epidermal growth factor receptor mutations: a pooled analysis of published reports. Cancer Sci. 2011; 5: 1032-7. http: //dx.doi. org/10.1111/j.1349-7006.2011.01887.x 